\title{
Ulcerative Colitis: Disease Burden, Impact on Daily Life, and Reluctance to Consult Medical Professionals: Results from a Japanese Internet Survey
}

\author{
Toshifumi Hibi $^{a}$ Toyomi Ishibashi $^{a}$ Yuka lkenoue ${ }^{b}$ Ryoichi Yoshihara ${ }^{c}$ \\ Akiko Nihei $^{d}$ Taku Kobayashi $^{\mathrm{a}}$ \\ ${ }^{a}$ Center for Advanced IBD Research and Treatment, Kitasato University, Kitasato Institute Hospital, Tokyo, Japan; \\ ${ }^{\mathrm{b}}$ Medical Science Group, Department of Medical, EA Pharma Co., Ltd., Tokyo, Japan; ' Department of Medical

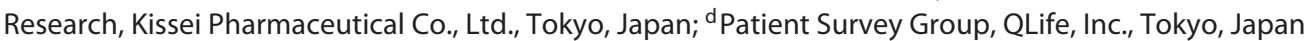

\section{Keywords}

Bowel urgency - Bowel incontinence - Stool frequency ·

Rectal bleeding · Ulcerative colitis

\begin{abstract}
Background and Aim: The prevalence of ulcerative colitis has increased in Asian populations in recent years. This Japanese internet survey investigated the symptoms, impact, and treatment of ulcerative colitis, and communication between patients and medical professionals. Methods: This was a non-interventional analysis of responses from participants with ulcerative colitis who had regularly visited medical providers for their disease in the past year. Results: In 501 evaluable participants, the mean age was 39.8 years and mean disease duration was 7.6 years. Ulcerative colitis had a "significant impact" on daily life in $43.5 \%$ of participants who experienced bowel urgency and $48.6 \%$ who experienced bowel incontinence. Although the prevalence of bowel urgency and bowel incontinence was associated with higher stool frequency and rectal bleeding scores ( $p$ value for trend $<0.0001$ ), they still existed even in patients without frequent stools or rectal bleeding. Around $30 \%$ of participants hesitated to discuss symptoms such as bowel incontinence with
\end{abstract}

\begin{tabular}{ll}
\hline KARGER & (c) 2020 The Author(s) Karger \\
& Published by S. Karger AG, Basel Open ciccess \\
karger@karger.com & This article is licensed under the Creative Commons Attribution- \\
www.karger.com/iid & NonCommercial-NoDerivatives 4.0 International License (CC BY- \\
& NC-ND) (http://www.karger.com/Services/OpenAccessLicense). \\
Usage and distribution for commercial purposes as well as any dis- \\
tribution of modified material requires written permission.
\end{tabular}

a medical professional. Approximately three-quarters preferred to use websites for medical information. Most participants (78.0\%) had used topical treatments. However, $25.7 \%$ were hesitant to use such treatments due to concerns about discomfort (48.1\%) and administration difficulty (47.3\%). Conclusions: Ulcerative colitis significantly affects daily life, largely due to symptoms such as bowel urgency and bowel incontinence. Despite desiring to improve bowel incontinence, patients are embarrassed to consult physicians or nurses. Therefore, medical professionals should make an active effort to draw out patients' individual concerns, including symptoms that patients may not initially feel able to talk about openly.

(c) 2020 The Author(s)
Published by S. Karger AG, Basel

\section{Introduction}

Ulcerative colitis is a non-specific inflammatory bowel disease (IBD) of unknown cause that is characterized by alternating periods of remission and relapse $[1,2]$. $\mathrm{Pa}$ tients can develop ulcerative colitis at any age, from childhood onwards, but the incidence peaks in early adulthood [3], and is similar between men and women $[1,4]$. The 
prevalence in Asian populations appears to have increased in recent years [5-7], and Asian patients often present with more severe symptoms [8].

The major symptoms of ulcerative colitis are chronic abdominal pain, diarrhea, and rectal bleeding $[1,9]$. Patients who have distal ulcerative colitis may have mild symptoms $[10,11]$. However, patients with rectal dysfunction may experience bowel urgency or bowel incontinence, tenesmus, and a sense of incomplete evacuation, all of which can significantly reduce quality of life (QoL) $[12,13]$. In many reports, bowel urgency and bowel incontinence are key elements of patient burden in ulcerative colitis [14-16]. The importance of bowel urgency is also emphasized in the U.S. guidelines and is used for diagnosis and as an index for treatment success [17]. However, a report from the Ministry of Health, Labour and Welfare of Japan ("Investigation and research for intractable IBD" [18]) on patients with ulcerative colitis mentions rectal bleeding (approximately $40 \%$ of patients), diarrhea (40\%), and abdominal pain (25\%), but presents no data for bowel urgency or bowel incontinence. Thus, data for these key symptoms are lacking in the Japanese realworld population.

No definitive therapy for ulcerative colitis has yet been established $[5,19]$. The goals of current treatment are to induce remission of active disease and maintain durable remission over the long term, whilst preserving a good QoL and reducing the need for surgery $[1,17,19]$. Moreover, although it is clear that ulcerative colitis places a high disease burden upon patients, there remains a large perception gap between physicians and patients [20]. In particular, patients may find it difficult or embarrassing to discuss problems in daily life caused by bowel incontinence or frequent use of the toilet [21].

The objective of this survey was to use an Internetbased questionnaire to investigate the problems for patients with ulcerative colitis, including symptoms, impact on daily life, therapy and satisfaction, communications with medical professionals, and use of topical preparations.

\section{Methods}

Survey Design and Participants

This was an Internet-based survey using a disease-specific questionnaire. No treatments were offered, and there was no randomization or blinding. QLife, Inc. (Tokyo, Japan) conducted the research from February 2019 to March 2019. The survey was registered with the University hospital Medical Information Network with the identification number UMIN000035731.
Table 1. Subject demographic and clinical characteristics

\begin{tabular}{|c|c|}
\hline Characteristic, $n(\%)$ & $\begin{array}{l}\text { Survey } \\
\text { participants } \\
(n=501)\end{array}$ \\
\hline Age, years, mean (SD) & $39.8(12.4)$ \\
\hline \multicolumn{2}{|l|}{ Gender } \\
\hline Female & $278(55.5)$ \\
\hline Male & $223(44.5)$ \\
\hline Duration of ulcerative colitis, years ${ }^{\mathrm{a}}$, mean (SD) & $7.6(8.6)$ \\
\hline \multicolumn{2}{|l|}{ Classification $^{\mathrm{b}}$} \\
\hline Total colitis & $240(47.9)$ \\
\hline Left-sided colitis & $94(18.8)$ \\
\hline Proctitis & $126(25.1)$ \\
\hline Unknown & $41(8.2)$ \\
\hline Past surgery, yes ${ }^{\mathrm{c}}$ & $28(5.6)$ \\
\hline \multicolumn{2}{|l|}{ Drug treatment ${ }^{\mathrm{d}}$} \\
\hline Oral & $448(89.4)$ \\
\hline Topical & $210(41.9)$ \\
\hline Injection & $106(21.2)$ \\
\hline Other & $57(11.4)$ \\
\hline \multicolumn{2}{|l|}{ Disease status ${ }^{\mathrm{e}}$} \\
\hline \multicolumn{2}{|l|}{ Stool frequency score: Q9 } \\
\hline 0 (Same as usual) & $283(56.5)$ \\
\hline 1 (1-2 stools more than usual) & $101(20.2)$ \\
\hline 2 (3-4 stools more than usual) & $63(12.6)$ \\
\hline 3 ( $\geq 5$ stools more than usual) & $54(10.8)$ \\
\hline \multicolumn{2}{|l|}{ Rectal bleeding score: Q11-Q12 } \\
\hline 0 (No blood seen) & $255(50.9)$ \\
\hline 1 (Streaks of blood with stool less than & \\
\hline half the time) & $140(27.9)$ \\
\hline $\begin{array}{l}2 \text { (Obvious blood with stool most of the } \\
\text { time) }\end{array}$ & $75(15.0)$ \\
\hline 3 (Mostly blood) & $16(3.2)$ \\
\hline Unknown & $15(3.0)$ \\
\hline
\end{tabular}

a Based on single-choice answer: At what age were you diagnosed with ulcerative colitis? ${ }^{\mathrm{b}}$ Based on single-choice answer: What type of ulcerative colitis do you have? ${ }^{c}$ Based on yes/no answer: Have you ever had surgery for ulcerative colitis? ${ }^{\mathrm{d}}$ Based on multiple-choice answer: What medicines are you currently prescribed? ${ }^{\text {e }}$ Stool frequency and rectal bleeding scores were based on Mayo subscores derived from the answers to Q9 and Q11-Q12. Q9 (single-choice answer): What was the frequency of defecation in the past 2 weeks? Q11 (single-choice answer): How frequently did you have rectal bleeding when you defecated in the past 2 weeks? Q12 (single-choice answer): Describe the bleeding.

Survey participants were recruited from an IBD patient panel of QLife, Inc. Subjects with ulcerative colitis who had visited medical providers regularly in the past year were included. There were no specific exclusion criteria, but there were discontinuation criteria for the survey, as follows: a serious ethical policy violation or a serious deviation from the research plan during the research period, a request to discontinue by the participant, noncompliance with the survey plan, or the survey operator determined that it was necessary to stop the survey.
Inflamm Intest Dis 2020;5:27-35 DOI: $10.1159 / 000505092$
Hibi/Ishibashi/Ikenoue/Yoshihara/Nihei/ Kobayashi 
Fig. 1. Incidence of bowel urgency or bowel incontinence (in the past 2 weeks). a Bowel urgency. Q13: How frequently did you feel anxious about not making it to a toilet in time in the past 2 weeks? b Bowel incontinence. Q14: How frequently did you experience underwear soiling in the past 2 weeks? $(n=501)$.

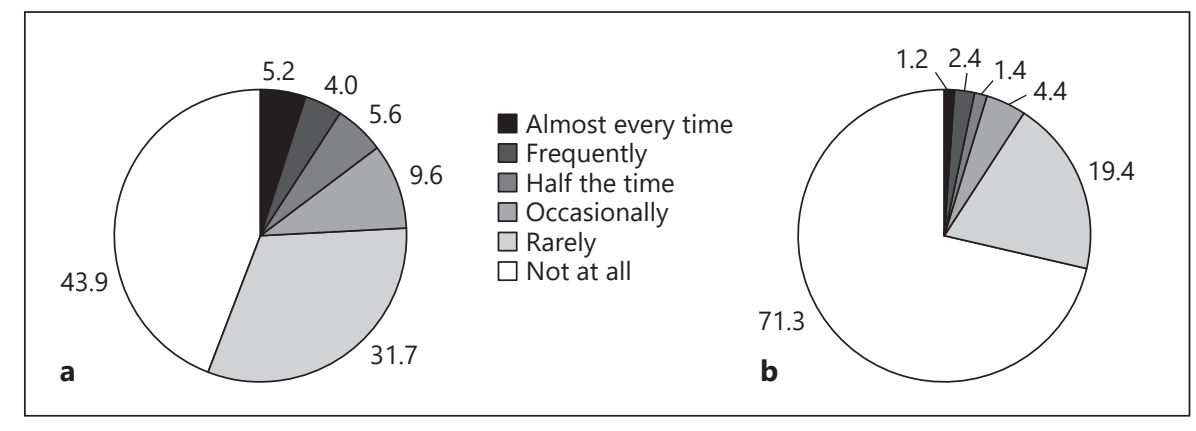

Survey Questions and Procedures

The survey (online suppl. Table S1; for all online suppl. material, see www.karger.com/doi/10.1159/000505092) comprised 30 questions, divided into the following 4 categories: "Demographics, symptoms, and treatment" (Q1-Q15), "Impact on daily life" (Q16-Q23), "Communications with medical professionals” (Q24Q26), and "Use of topical preparations" (Q27-Q30). Participants responded to each survey question with a single-choice answer or multiple-choice answer. The survey was hosted in a secure environment. Participants were given a survey guide and could ask for clarification, if necessary, via a web-based form.

Questions on stool frequency (Q9) and rectal bleeding (Q11 and Q12) were based on the Mayo score [22, 23]. Bowel urgency and bowel incontinence were derived using Q13 and Q14, respectively. The symptoms experienced by each participant were derived from Q16 ("What symptom[s] do you want to improve?").

\section{Statistical Analysis}

The target number of participants was $\geq 500$; it was considered that it would be feasible to recruit and obtain data from this number of subjects within the time frame of the study. Answers to the survey questions were summarized descriptively. To calculate statistical significance at a level of $<0.05$, the Cochran-Armitage test for trend was used. $\mathrm{R}$ version 3.5.3 was used for the statistical analyses [24].

\section{Results}

A total of 509 participants completed the survey of whom 501 were confirmed to have had a recent hospital visit (within the past 3 months) for ulcerative colitis and were included in the statistical analysis. The full survey results are reported in online supplementary Table S1, and the answers are summarized below.

\section{Demographics, Symptoms, and Treatment (Q1-Q15)}

Demographic and clinical characteristics, including symptom frequency and treatments, are reported in Table 1 (based on Q1-Q15). The mean age was 39.8 years, and $55.5 \%$ of participants were female. The mean disease duration was 7.6 years, and almost half of participants
(47.9\%) had total colitis. Of the 501 subjects evaluated, 28 (5.6\%) had undergone surgery for ulcerative colitis. The most common drug treatment used was oral in 448 (89.4\%) participants, followed by topical in 210 (41.9\%).

Stool frequency score was 0 in the majority of participants $(56.5 \%)$, but $10.8 \%$ had a score of 3 ( $\geq 5$ stools more than normal). Similarly, most patients (50.9\%) had a rectal bleeding score of 0 (no blood seen; Table 1). Of patients who had rectal bleeding (231/501, 46.1\%), 140/231 (60.6\%) had a subscore of 1 (streaks of blood with stool less than half the time), 75/231 (32.5\%) had a score of 2 (obvious blood with stool most of the time), and 16/231 (6.9\%) had a score of 3 (mostly blood; online suppl. Table S1).

Bowel urgency was assessed in Q13 ("How frequently did you feel anxious about not making it to a toilet in time in the past 2 weeks?") and bowel incontinence in Q14 ("How frequently did you experience underwear soiling in the past 2 weeks?"). Figure $1 \mathrm{a}$ and $\mathrm{b}$ show the responses to Q13 and Q14, respectively, with 281/501 (56.1\%) participants experiencing some level of bowel urgency and 144/501 (28.7\%) experiencing some level of bowel incontinence.

In response to Q15 ("In the past 2 weeks, how frequently did you experience the urge to defecate even when your intestine was empty?"), most participants answered "not at all" (48.3\%) or "rarely" (less than once in 5 times; $27.9 \%$ ).

\section{Impact on Daily Life (Q16-Q23)}

The impact of ulcerative colitis on daily life was investigated first via Q16 ("What symptom[s] do you want to improve?"). The most frequently reported symptoms were bowel urgency $(62.5 \%)$, diarrhea $(60.7 \%)$, rectal bleeding (59.7\%), and abdominal pain (58.1\%; Q16). When asked to specify which one of the symptoms from Q16 they would most like to improve (Q17), the answers were bowel urgency (25.0\%), followed by rectal bleeding 
Table 2. Impact of ulcerative colitis on daily life, by symptom $(n=501)$

\begin{tabular}{|c|c|c|c|c|c|c|}
\hline Participants with symptom & $291(58.1)$ & $304(60.7)$ & $299(59.7)$ & $313(62.5)$ & $185(36.9)$ & $195(38.9)$ \\
\hline \multicolumn{7}{|c|}{ Q18 by Q16 symptoms: To what extent is your daily life impacted by ulcerative colitis? } \\
\hline Barely impacted & $45 / 291(15.5)$ & $59 / 304(19.4)$ & $54 / 299(18.1)$ & $52 / 313(16.6)$ & $21 / 185(11.4)$ & $33 / 195(16.9)$ \\
\hline Not impacted & $7 / 291(2.4)$ & $8 / 304(2.6)$ & $11 / 299(3.7)$ & $5 / 313(1.6)$ & $6 / 185(3.2)$ & $1 / 195(0.5)$ \\
\hline
\end{tabular}

Data are shown as $n(\%)$.
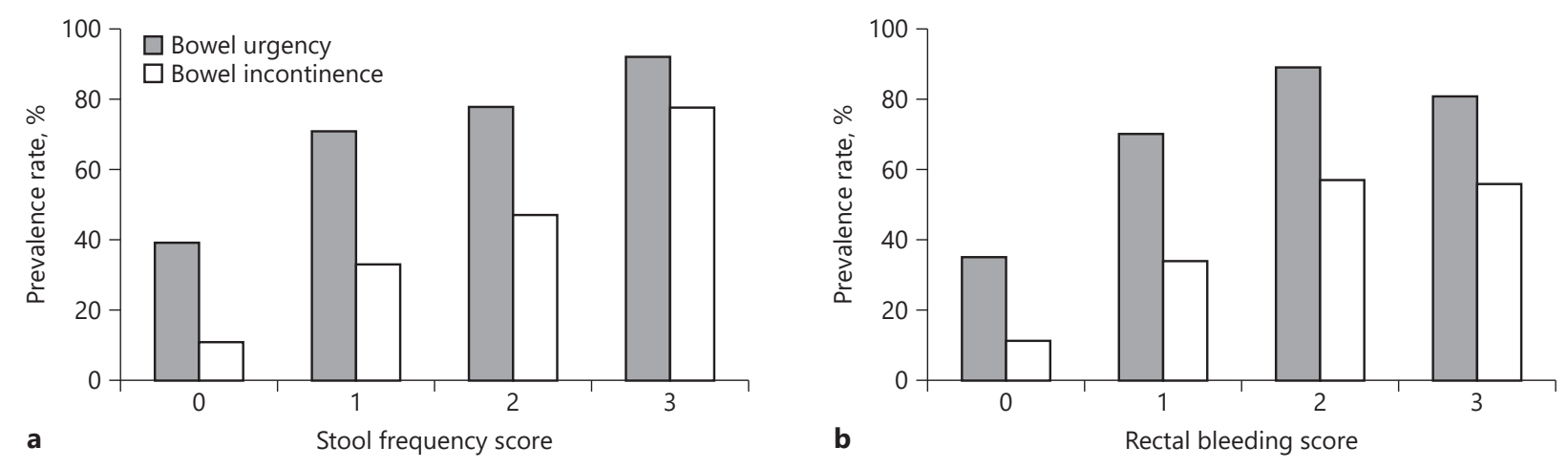

Fig. 2. Frequency of bowel urgency and bowel incontinence according to (a) stool frequency score $\mathrm{e}^{\mathrm{a}, \mathrm{b}}$ and (b) rectal bleeding score ${ }^{\mathrm{a}, \mathrm{c}}$. ${ }^{\mathrm{a}}$ Trend $p<0.0001$, calculated using the Cochran-Armitage test. ${ }^{\mathrm{b}}(n=473)$, excluding participants who had surgery. ${ }^{c}(n=458)$, excluding participants who had surgery and who answered "unknown" for rectal bleeding.

(21.4\%), abdominal pain (19.6\%), diarrhea (13.8\%), bowel incontinence (10.4\%), and sense of incomplete evacuation $(5.2 \%)$.

The proportion of participants who stated that ulcerative colitis "significantly impacted" their daily life (Q18) was highest for participants who experienced bowel urgency or bowel incontinence ( 43.5 and $48.6 \%$, respectively; Table 2).

The relationships between bowel urgency and bowel incontinence and stool frequency and rectal bleeding scores were also investigated (Fig. 2). In general, higher stool frequency and rectal bleeding scores were associated with higher prevalence of bowel urgency and bowel incontinence ( $p$ value for trend $<0.0001$ ). However, there was still a relatively high incidence of bowel urgency and bowel incontinence even in participants with a stool frequency score of 0 (39 and $11 \%$, respectively) or a rectal bleeding score of 0 (35 and 11\%, respectively).

Table 3 summarizes the analysis of participant baseline factors and the incidence of bowel urgency and bowel incontinence. There were no significant differences in the prevalence of bowel urgency and bowel incontinence by disease classification. There was a significant correlation between increasing age and bowel incontinence ( $p$ value for trend $=0.0014$ ), and there was also a significant correlation between bowel urgency and bowel incontinence ( $p$ value for trend $<0.0001$ ).

Working environment (including workplace support, peer understanding, and toilet access) was assessed in Q20-Q23 (online suppl. Table S1). Regarding current oc- 
Table 3. Characteristics of participants who experienced bowel urgency or bowel incontinence

\begin{tabular}{|c|c|c|c|c|c|c|c|c|}
\hline Characteristic & yes, $n$ & no, $n$ & incidence, \% & $p$ value $^{\mathrm{a}}$ & yes, $n$ & no, $n$ & incidence, \% & $p$ value $^{\mathrm{a}}$ \\
\hline \multicolumn{9}{|l|}{ Gender } \\
\hline Male & 114 & 96 & 54.3 & & 55 & 155 & 26.2 & \\
\hline Female & 151 & 112 & 57.4 & & 72 & 191 & 27.4 & \\
\hline \multicolumn{9}{|l|}{ Age, years } \\
\hline $30 \mathrm{~s}$ & 60 & 48 & 55.6 & & 26 & 82 & 24.1 & \\
\hline $40 \mathrm{~s}$ & 84 & 63 & 57.1 & & 40 & 107 & 27.2 & \\
\hline $50 s+$ & 64 & 44 & 59.3 & & 40 & 68 & 37.0 & \\
\hline \multicolumn{9}{|l|}{ Disease duration, years } \\
\hline$<5$ & 140 & 114 & 55.1 & 0.4279 & 58 & 196 & 22.8 & 0.0326 \\
\hline \multicolumn{9}{|l|}{ Disease classification $^{b}$} \\
\hline Left-sided colitis & 59 & 29 & 67.0 & & 26 & 62 & 29.5 & \\
\hline Proctitis & 69 & 57 & 54.8 & & 34 & 92 & 27.0 & \\
\hline \multicolumn{9}{|l|}{ Bowel urgency } \\
\hline Almost every time & - & - & - & - & 20 & 5 & 80.0 & $<0.0001$ \\
\hline Frequently & - & - & - & & 14 & 4 & 77.8 & \\
\hline Half the time & - & - & - & & 16 & 7 & 69.6 & \\
\hline Occasionally & - & - & - & & 27 & 20 & 57.4 & \\
\hline Rarely & - & - & - & & 47 & 105 & 30.9 & \\
\hline Never & - & - & - & & 3 & 205 & 1.4 & \\
\hline \multicolumn{9}{|l|}{ Bowel incontinence } \\
\hline Almost every time & 5 & 0 & 100.0 & $<0.0001$ & - & - & - & - \\
\hline Frequently & 10 & 0 & 100.0 & & - & - & - & \\
\hline
\end{tabular}

${ }^{\text {aTrend }} p$ calculated using the Cochrane-Armitage test. ${ }^{b}$ Four hundred thirty-three participants included; 40 excluded from analysis as they did not know the disease classification. Bold text indicates statistical significance.

cupation, "office worker" accounted for 157 responses (31.3\%), followed by "part-time employment" (84 responses, $16.8 \%$ ) and "field worker" (62 responses, $12.4 \%)$. Responses to Q21 showed that $405(80.8 \%)$ respondents had discussed their disease at work/school. Among these $405,250(61.8 \%)$ responded that they had sufficient support at work/school, 89 respondents (22\%) said not enough support was provided, and 66 respondents (16.3\%) reported receiving no support. Regarding impact of disease on their work/school, $24.8 \%$ of respondents replied that they "took sick leave from work," $18.4 \%$ "quit their job," 9.0\% "changed work to part-time," and 7.4\% "changed role within a company." No statistically signifi- cant correlation between working environment and experiencing bowel urgency or incontinence was observed in this analysis.

\section{Communications with Medical Professionals (Q24- Q26)}

Around $30 \%$ of survey participants who experienced bowel incontinence felt embarrassed to consult medical professionals about this symptom (Fig. 3a), and the results of the survey suggest that most subjects with ulcerative colitis use medical information websites $(74.3 \%)$ or patient blogs (57.0\%) as sources of information for such symptoms (Fig. 3b). The percentage of those who felt it 


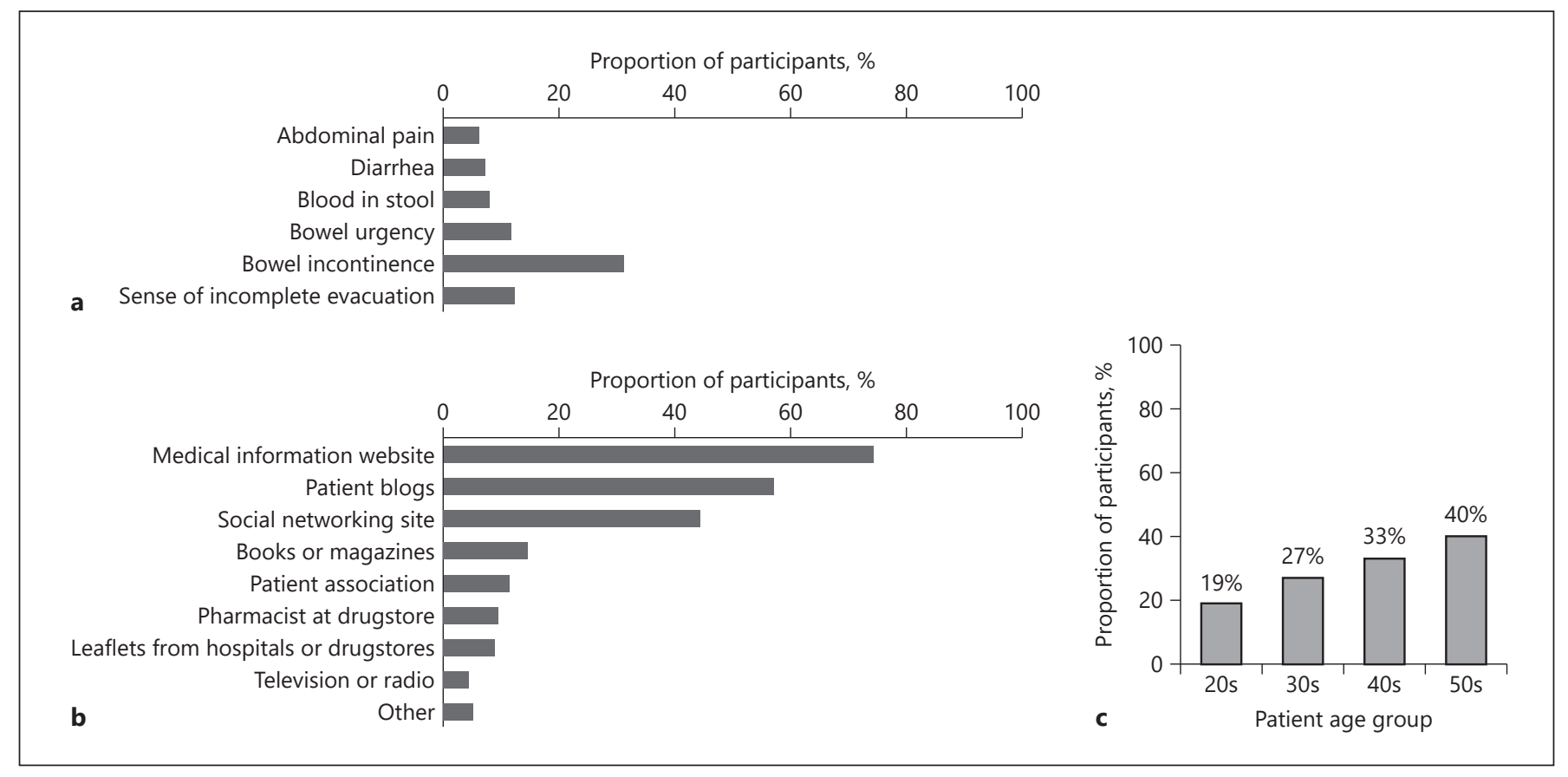

Fig. 3. Participants who reported embarrassment about discussing symptoms with medical professionals. a Embarrassment about symptoms according to those who experienced each symptom $(\mathrm{Q} 25 \times \mathrm{Q} 16)$. b Alternative sources of information (Q26). c The proportion of participants who answered that they found it difficult to consult about bowel incontinence by age $(\mathrm{Q} 25 \times \mathrm{Q} 16 \times \mathrm{Q} 1)^{\mathrm{a}}$. ${ }^{\text {a }}$ Trend $p=0.053$ calculated using the Cochrane-Armitage test.

was difficult to consult with medical professionals about bowel incontinence tended to increase with age (Fig. 3c).

Use of Topical Preparations (Q27-Q30)

The majority of participants (78.0\%) surveyed had used topical preparations to improve symptoms of ulcerative colitis (online suppl. Table S1, Q27-Q28), with $65.7 \%$ expecting such preparations to improve rectal bleeding, and $45.7 \%$ expecting them to improve diarrhea.

Furthermore, $74.3 \%$ of the survey participants would like to try topical preparations if they could expect symptom improvement, but the remaining $25.7 \%$ of individuals were reluctant to try them (Q29-Q30), with the major reasons including concerns about discomfort after treatment (48.1\%) and the difficulty of administration (47.3\%).

\section{Discussion}

This internet-based survey aimed to clarify the daily issues facing 501 Japanese patients with ulcerative colitis. The results indicate that more than half of patients had bowel urgency and around 30\% had bowel incontinence. While diarrhea, abdominal pain, and rectal bleeding are symptoms that most patients experience $[1,9]$, bowel urgency, bowel incontinence, and a sense of incomplete evacuation are limited to a smaller proportion of patients. Therefore, we analyzed the impact on daily life for each patient who wanted to improve these symptoms. While the prevalence of bowel urgency was similar to that of other major complaints, the proportion of participants who stated that ulcerative colitis "significantly impacted" their daily life was highest for participants who experienced bowel urgency or bowel incontinence (43.5 and $48.6 \%$, respectively). These results are in line with previously published data, which indicated that bowel urgency and bowel incontinence are key elements of patient burden [14-17], and these 2 symptoms clearly constitute an issue that must be recognized in order to improve treatment outcomes for patients.

The high prevalence of bowel urgency and bowel incontinence in our survey are similar to those reported previously. In a study of 247 individuals from Ireland with ulcerative colitis or Crohn's disease, $50.0 \%$ of pa- 
tients with inactive disease and $83.8 \%$ with active disease reported bowel urgency, while 8.5 and $31.3 \%$, respectively, had bowel incontinence [14]. Among the patients with ulcerative colitis in that study $(n=85)$, the most burdensome symptom was bowel urgency [14].

The occurrence of bowel urgency and bowel incontinence also differs according to Montreal classification of ulcerative colitis. In a Brazilian study of IBD patients, of 151 with ulcerative colitis who were analyzed, bowel urgency was reported in $87.7 \%$ of patients with extensive colitis, $88 \%$ with left-sided colitis, and $66.7 \%$ with proctitis, while bowel incontinence was reported in 59.6, 70, and $55.6 \%$, respectively [25]. In the current survey, there was no significant difference in prevalence between the disease classifications of ulcerative colitis. Medical care for bowel urgency and bowel incontinence is required even for proctitis that appears to be mild, highlighting the importance of these 2 symptoms. A correlation was observed between stool frequency and rectal bleeding scores and the existence of bowel urgency and bowel incontinence in this survey. However, although some participants had stool frequency and rectal bleeding scores of 0 , bowel urgency and bowel incontinence were still reported. This implies that symptoms such as stool frequency or rectal bleeding cannot reliably predict bowel urgency or bowel incontinence. Bowel urgency is known to be a prevalent symptom in ulcerative colitis [14], and its presence may alert physicians to a problem prior to observation of unusual stool frequency or rectal bleeding. Thus, it is important to ask patients about all of their symptoms, rather than focusing on stool frequency and rectal bleeding alone [26].

Not unexpectedly, patients with ulcerative colitis are embarrassed and hesitate to consult medical professionals about bowel incontinence. Discussions of particularly bothersome symptoms should form a key part of clinic visits, in order to improve patient QoL $[14,15,27]$. The Mayo score [22,23], which is commonly used to monitor treatment efficacy and the patient's condition, focuses on stool frequency, rectal bleeding, endoscopic findings of mucosal condition, and physician's global assessment. Thus, future clinical studies may also need to assess additional patient burdens caused by bowel urgency and bowel incontinence. Active questioning by medical professionals as to the existence of bowel urgency and bowel continence in their patients is also warranted, particularly in older patients, as there is a tendency for greater reticence in discussing symptoms with increasing age. In recent years, efforts have been made to enhance patient communication with medical professionals using desktop or phone applications that record changes in the pa-

Survey of Ulcerative Colitis in Japan tient's own condition. However, to make it easier for patients to discuss bowel urgency or bowel incontinence, these must be included in the application as separate symptoms; such medical applications may require further optimization to fully meet the needs of clinicians and their patients.

Rectal lesions may be one cause of bowel urgency and bowel incontinence; thus, topical preparations that improve rectal lesions may alleviate those symptoms [28, 29]. In this survey, participants reported that they would use topical preparations to relieve symptoms such as rectal bleeding (65.7\%) or diarrhea (45.7\%), but few stated that they would expect such treatment to improve rectal symptoms such as bowel urgency (29.9\%), bowel incontinence (15.6\%), or sense of incomplete evacuation (13\%). It seems that patients with ulcerative colitis are largely unaware of the benefits that can be obtained by the use of topical therapies; this result is confirmed by previous studies showing that topical therapies are underused [29, 30]. There is clearly a potential communication barrier between medical professionals and patients that needs to be overcome.

There are several potential limitations to this survey that must be considered when interpreting the data. Primarily, the data were self-reported by subjects without medical confirmation, and impact on daily life is subjective; thus, it is difficult to quantify outcomes and it is only possible to compare overall trends between this and other analyses. Because the answers were self-reported, it is also difficult to differentiate active disease from remission. In addition, participants in this survey were all adults, so we are unable to comment on the burdens facing younger patients with this distressing condition. However, the use of an independently curated panel of patients to give broad coverage and reduce selection bias is a key strength of this survey, along with the high completion rates and low rates of missing data observed.

\section{Conclusions}

Ulcerative colitis significantly affected the daily life of the respondents of this survey, largely due to symptoms such as bowel urgency, bowel incontinence, and rectal bleeding. Despite wanting to improve bowel incontinence, patients report also being embarrassed to consult physicians or nurses. Therefore, medical professionals should actively query patients about all symptoms, not just bowel frequency and rectal bleeding, to optimize individual treatment. 


\section{Acknowledgment}

The authors would like to thank Sally-Anne Mitchell, PhD, of Edanz Medical Writing for providing medical writing support, which was funded by EA Pharma Co., Ltd. (Tokyo, Japan) and Kissei Pharmaceutical Co., Ltd. (Nagano, Japan), in accordance with Good Publication Practice 3 guidelines (http://www.ismpp.org/ gpp3).

\section{Statement of Ethics}

This research was approved by the Takahashi clinical Institutional Review Board on January 15, 2019 prior to initiation of any survey procedures. The conduct of this survey conformed to all applicable national and international ethical guidelines for medical and health research involving human subjects. All participants gave informed consent prior to commencing the survey.

\section{Disclosure Statement}

T.K., T.I., and T.H. were paid an advisory fee for this survey. T.K. also reports lecture fees from Abbvie GK, Alfresa Pharma Corporation, Takeda Pharmaceutical Co., Ltd., Mitsubishi Tanabe Pharma Corporation, Pfizer Japan Inc., Mochida Pharmaceutical Co., Ltd., and Janssen Pharmaceutical K.K., and research grants from Otsuka Holdings Co., Ltd., JIMRO Co., Ltd., EA Pharma Co., Ltd., Abbvie GK, Zeria Pharmaceutical Co., Ltd., and Nippon Kayaku, Co., Ltd. T.H. also reports lecture fees from Mitsubishi Tanabe Pharma Corporation, Takeda Pharmaceutical Co., Ltd., Aspen Japan Co., Ltd., and Janssen Pharmaceutical K.K., and research grants from Mochida Pharmaceutical Co., Ltd., Zeria Pharmaceutical Co., Ltd., EA Pharma Co., Ltd., Nippon Kayaku, Co., Ltd., Otsuka Holdings Co., Ltd., JIMRO Co., Ltd., and Abbvie GK. A.N. has no conflicts of interest to declare. Y.I. is an employee of EA Pharma Co., Ltd., and R.Y. is an employee of Kissei Pharmaceutical Co., Ltd.

\section{Funding Sources}

This survey was funded by EA Pharma Co., Ltd., and Kissei Pharmaceutical Co., Ltd.

\section{Author Contributions}

T.I., Y.I., R.Y., and T.H. contributed to the survey design. T.K., T.I., A.N., and T.H. contributed to data analysis and interpretation. T.K., T.I., A.N., Y.I., and R.Y. contributed to manuscript development. T.K. and T.H. made the final decision to submit the manuscript. All of the authors reviewed and approved the final manuscript.

\section{References}

1 Adams SM, Bornemann PH. Ulcerative colitis. Am Fam Physician. 2013 May;87(10): 699-705.

2 Ordás I, Eckmann L, Talamini M, Baumgart DC, Sandborn WJ. Ulcerative colitis. Lancet. 2012 Nov;380(9853):1606-19.

3 Herrinton LJ, Liu L, Lewis JD, Griffin PM, Allison J. Incidence and prevalence of inflammatory bowel disease in a Northern California managed care organization, 1996-2002. Am J Gastroenterol. 2008 Aug;103(8):19982006.

4 Rosenblatt E, Kane S. Sex-specific issues in inflammatory bowel disease. Gastroenterol Hepatol (N Y). 2015 Sep;11(9):592-601.

5 Masaki T, Kishiki T, Kojima K, Asou N, Beniya A, Matsuoka H. Recent trends (2016-2017) in the treatment of inflammatory bowel disease. Ann Gastroenterol Surg. 2018 Jun;2(4): 282-8.

6 Prideaux L, Kamm MA, De Cruz PP, Chan $\mathrm{FK}, \mathrm{Ng}$ SC. Inflammatory bowel disease in Asia: a systematic review. J Gastroenterol Hepatol. 2012 Aug;27(8):1266-80.

7 Hou JK, El-Serag H, Thirumurthi S. Distribution and manifestations of inflammatory bowel disease in Asians, Hispanics, and African Americans: a systematic review. Am J Gastroenterol. 2009 Aug;104(8):2100-9.
8 Castaneda G, Liu B, Torres S, Bhuket T, Wong RJ. Race/ethnicity-specific disparities in the severity of disease at presentation in adults with ulcerative colitis: A cross-sectional study. Dig Dis Sci. 2017 Oct;62(10):2876-81.

9 Ungaro R, Mehandru S, Allen PB, Peyrin-Biroulet L, Colombel JF. Ulcerative colitis. Lancet. 2017 Apr;389(10080):1756-70.

10 Lichtenstein GR, Hanauer SB, Sandborn WJ. Emerging treatment options in mild to moderate ulcerative colitis. Gastroenterol Hepatol (N Y). 2015 Mar;11(3 Suppl 1):1-16.

11 Singh S, Feuerstein JD, Binion DG, Tremaine WJ. AGA technical review on the management of mild-to-moderate ulcerative colitis. Gastroenterology. 2019 Feb;156(3):769-808. e29.

12 Norton C, Dibley LB, Bassett P. Faecal incontinence in inflammatory bowel disease: associations and effect on quality of life. J Crohn's Colitis. 2013 Sep; 7(8):e302-11.

13 Petryszyn PW, Paradowski L. Stool patterns and symptoms of disordered anorectal function in patients with inflammatory bowel diseases. Adv Clin Exp Med. 2018 Jun;27(6): 813-8.

14 Farrell D, McCarthy G, Savage E. Self-reported symptom burden in individuals with inflammatory bowel disease. J Crohn's Colitis. 2016 Mar; 10(3):315-22.
15 Carpio D, López-Sanromán A, Calvet X, Romero C, Cea-Calvo L, Juliá B, et al. Perception of disease burden and treatment satisfaction in patients with ulcerative colitis from outpatient clinics in Spain: UC-LIFE survey. Eur J Gastroenterol Hepatol. 2016 Sep;28(9): 1056-64.

16 Dibley L, Bager P, Czuber-Dochan W, Farrell D, Jelsness-Jørgensen LP, Kemp K, et al. Identification of research priorities for inflammatory bowel disease nursing in Europe: A Nurses-European Crohn's and Colitis Organisation Delphi survey. J Crohn's Colitis. 2017 Mar;11(3):353-9.

17 Rubin DT, Ananthakrishnan AN, Siegel CA, Sauer BG, Long MD. ACG clinical guideline: ulcerative colitis in adults. Am J Gastroenterol. 2019 Mar;114(3):384-413.

18 Japan Ministry of Health. Labor and Welfare [Internet]. Investigation and research for intractable inflammatory bowel disease [cited 2019 August 12]. Available from: http://www. ibdjapan.org/members/.

19 Ahmad H, Kumar VL. Pharmacotherapy of ulcerative colitis - current status and emerging trends. J Basic Clin Physiol Pharmacol. 2018 Nov;29(6):581-92. 
20 Peyrin-Biroulet L, Van Assche G, Sturm A, Gisbert JP, Gaya DR, Bokemeyer B, et al. Treatment satisfaction, preferences and perception gaps between patients and physicians in the ulcerative colitis CARES study: A real world-based study. Dig Liver Dis. 2016 Jun; 48(6):601-7.

21 McMullan C, Pinkney TD, Jones LL, Magill L, Nepogodiev D, Pathmakanthan S, et al. Adapting to ulcerative colitis to try to live a 'normal' life: a qualitative study of patients' experiences in the Midlands region of England. BMJ Open. 2017 Aug;7(8):e017544.

22 Schroeder KW, Tremaine WJ, Ilstrup DM. Coated oral 5-aminosalicylic acid therapy for mildly to moderately active ulcerative colitis. A randomized study. N Engl J Med. 1987 Dec; 317(26):1625-9.
23 MDCalc [Internet]. Mayo score/disease activity index (DAI) for ulcerative colitis [cited 2019 August 12]. Available from: https:// www.mdcalc.com/mayo-score-disease-activity-index-dai-ulcerative-colitis\#evidence.

24 R Core Team [Internet]. R: A language and environment for statistical computing. $\mathrm{R}$ Foundation for Statistical Computing, Vienna, Austria; version 3.5.3: 11 March 2019 [cited 2019 August 12]. Available from: http:// www.R-project.org/.

25 Nóbrega VG, Silva IN, Brito BS, Silva J, Silva MC, Santana GO. The onset of clinical manifestations in inflammatory bowel disease patients. Arq Gastroenterol. 2018 Jul-Sep;55(3): 290-5.

26 Ford AC, Moayyedi P, Bercik P, Morgan DG, Bolino C, Pintos-Sanchez MI, et al. Lack of utility of symptoms and signs at first presentation as predictors of inflammatory bowel disease in secondary care. Am J Gastroenterol. 2015 May;110(5):716-24.
27 Ghosh S, Mitchell R. Impact of inflammatory bowel disease on quality of life: Results of the European Federation of Crohn's and Ulcerative Colitis Associations (EFCCA) patient survey. J Crohn's Colitis. 2007 Sep;1(1):1020.

28 Lie MR, Kanis SL, Hansen BE, van der Woude CJ. Drug therapies for ulcerative proctitis: systematic review and meta-analysis. Inflamm Bowel Dis. 2014 Nov;20(11):2157-78.

29 Gecse KB, Lakatos PL. Ulcerative proctitis: an update on the pharmacotherapy and management. Expert Opin Pharmacother. 2014 Aug; 15(11):1565-73.

30 Seibold F, Fournier N, Beglinger C, Mottet C, Pittet V, Rogler G; Swiss IBD cohort study group. Topical therapy is underused in patients with ulcerative colitis. J Crohn's Colitis. 2014 Jan;8(1):56-63. 